\title{
Shaking Table and Numerical Seismic Performance Evaluation of a Fluid Viscous- Dissipative Bracing System
}

\section{Stefano Sorace, ${ }^{\text {a) }}$ Gloria Terenzi, ${ }^{\text {b) }}$ and Fabio Fadi ${ }^{\text {a) }}$}

A shaking table campaign was carried out on a 2:3-scale two-story steel frame structure retrofitted by a dissipative bracing system incorporating pressurized fluid viscous spring-dampers. Up to $1.16 \mathrm{~g}$ peak ground accelerations were imposed in the most severe of the 33 tests developed. The response was always elastic, with maximum interstory drift ratios limited below $0.62 \%$, thanks to the high dissipative capacities of the protection technology, which produced equivalent linear viscous damping coefficients up to $37.5 \%$. The experimental data were integrated with a numerical enquiry on the test structure in its original unbraced configuration, which showed interstory drift reductions ranging from about $80 \%$ to about $90 \%$, when passing to dissipative braced conditions. A final performance-based analysis developed in terms of interstory drifts and beam and column rotations, by referring to the criteria formulated in ASCE/SEI 41-06 Standard, emphasized 3 through 5 enhancements of building performance in retrofitted conditions, for the four earthquake levels examined.

\footnotetext{
a) Dept. of Civil Engineering and Architecture, University of Udine, Via delle Scienze 208, 33100 Udine, Italy

b) Dept. of Civil and Enviromental Engineering, University of Florence, Via S. Marta 3, 50139 Florence, Italy
} 